\title{
EFFECT OF HYDRATED LIME ON THE BOND BETWEEN ASPHALT AND \\ RECYCLED CONCRETE AGGREGATES
}

\author{
A.R. Pasandín ${ }^{1 *}$ I. Pérez ${ }^{1}, B$. Gómez-Meijide ${ }^{l}$ and N. Pérez-Barge $e^{l}$ \\ 1 Universidade da Coruña. E. T. S. I. Caminos, Canales y Puertos. Campus de Elviña s/n, \\ 15071 A Coruña, Spain \\ ${ }^{*}$ Corresponding author: tel.: +34-981167000. Fax: +34-981167170 \\ E-mail addresses: arodriguezpa@udc.es (A.R.Pasandin), iperez@udc.es (I. Pérez), \\ bgomez@udc.es (B.Gómez-Meijide),natalia.pbarge@udc.es (N.Pérez-Barge)
}

\begin{abstract}
In this investigation, rolling bottle tests and boiling water tests were performed to evaluate the effect of hydrated lime on the adhesion between recycled concrete aggregates (RCA) and the asphalt binder. RCA from construction and demolition waste (C\&DW) were used in this investigation. To generalize the findings, three asphalt penetration grades were analysed: $\mathrm{B} 40 / 50, \mathrm{~B} 60 / 70$ and B150/200. The results indicate that the use of hydrated lime does not improve the RCA-aggregate bond. Additionally, the results indicate that a higher asphaltaggregate adhesion correlates to a lower asphalt penetration grade.

Keywords: asphalt, FTIR-ATR, recycled concrete aggregates, hydrated lime, bond.
\end{abstract}

\section{Introduction}

The use of recycled concrete aggregates (RCA) from construction and demolition waste (C\&DW) in place of natural aggregates in hot-mix asphalt (HMA) promote sustainable road pavement construction. Nevertheless, several studies have observed that because of an insufficient bond between the RCA and asphalt binder, HMA designed with RCA have shown poor water resistance (Paranavithana and Mohajerani, 2006; Pérez et al., 2007, 2010, 2012a and 2012b). Properly coating RCA with bitumen is more difficult than coating natural aggregates with bitumen because of the rough surface texture of the RCA. This surface texture can also affect the water resistance of the mixture. Water damage is one of main causes of the premature deterioration of flexible pavements (Caro et al., 2008); this damage causes stripping that negatively affects the durability of the mixtures. Thus, this poor moisture damage resistance of HMA composed of RCA must be improved to guarantee the sufficient durability of such 
mixtures. These improvements will promote their use in the road pavement construction industry and therefore their environmental benefits.

Numerous products and treatments that can improve the water resistance of HMA are available in the market, including liquid surfactants, fly ash, Portland cement or hydrated lime. The most utilized product is hydrated lime (Epps et al., 2003; Airey et al., 2008; Kim et al., 2012). Hydrated lime can be introduced in the mixture in three different methods (Button and Epps, 1983):

- Addition of hydrated lime to dry aggregates;

- Addition of hydrated lime to wet aggregates; and

- Addition of hydrated lime slurry to dry aggregates.

The present investigation analyses the effect hydrated lime on the bond between RCA and asphalt and the water damage resistance and durability of HMA composed of RCA. To conduct the analysis, three samples using hydrated lime and Portland cement as filler were manufactured. The hydrated lime was introduced in the samples by the three above mentioned techniques. A fourth sample, using only Portland cement as filler (without the introduction of hydrated lime), was used as a control sample. RCA from C\&DW have been used to conduct the investigation. To generalize the findings, three penetration grade asphalt binders were used: B40/50, B60/70 and B150/200. To perform the research, two types of laboratory tests were selected because of their rapidity and simplicity (Jo et al., 1997): the rolling bottle method (AENOR, 2011) and the boiling water test (ASTM, 2005).

\section{Materials and methods}

\subsection{Materials characterisation}

\subsubsection{Recycled concrete aggregates}

As stated above, the laboratory evaluation was conducted with RCA from C\&DW from residential buildings. The material was supplied by a recycling site in Madrid (Spain). RCA is 
mainly composed of petrous materials (89.3\%) (such as aggregates, concrete and mortar), particles of asphalt (6.5\%), masonry (3.6\%) and other components (0.6\%).

Table 1 describes the main properties of the RCA. The RCA water absorption is high, and the resistance to fragmentation is poor because of the attached mortar onto the RCA surface.

\subsubsection{Asphalt binder}

B40/50, B60/70 and B150/200 asphalt penetration grades were used in this investigation. Fourier Transform infrared spectroscopy by attenuated total reflectance (FTIR-ATR) (Bruker Vector 22) was conducted to determine the functional group differences between the three tested bitumen. Figure 1 shows the spectra obtained in wavenumbers ranging from 1900 to 500 $\mathrm{cm}^{-1}$ (Lu and Isacsson, 2002). In this range, two wavenumber values are particularly important. On the one hand, the absorbance band at approximately $1700 \mathrm{~cm}^{-1}$ is related to the carbonyl compounds $(\mathrm{C}=\mathrm{O})$, such as ketones, carboxylic acids and anhydrides. On the other hand, the absorbance band at approximately $1030 \mathrm{~cm}^{-1}$ is related to the sulphoxide compounds $(\mathrm{S}=0)$. An increase in carbonyl and sulphoxide compounds is generally observed in aged bitumen (Qin et al., 2014; Zhu et al., 2014) and thus in harder bitumen. As shown in figure 1 and as expected, bitumen B40/50 and B60/70 display FTIR-ATR spectra peaks at wavenumbers of approximately $1700 \mathrm{~cm}^{-1}$; these wavelengths were $1030 \mathrm{~cm}^{-1}$ higher and more similar than those obtained for B150/200, which is the softer bitumen.

\subsubsection{Portland cement}

Commercial grey Portland cement CEM II/B-M (V-L) $32.5 \mathrm{R}$ was used as control filler (mineral powder with size passing through the $0.063 \mathrm{~mm}$ sieve).

\subsubsection{Hydrated lime}

Commercial hydrated lime CL-90 S (minimum content of $\mathrm{CaO}$ and $\mathrm{MgO}: 90 \%$ ), with a grain size distribution shown in figure 2, was used as an anti-stripping additive. As noted above, hydrated lime was introduced into the mixture in the three abovementioned ways, which are described in detail below:

- In total, $1 \%$ of hydrated lime (Lesueur et al., 2013) by weight of the dry aggregates was added to the dry RCA; and $2 \%$ of Portland cement by weight of the dry RCA was also added. 
- In total, $1 \%$ of hydrated lime by weight of the dry aggregates was added to the saturatedsurface-dry (SSD) condition RCA; 2\% of Portland cement by weight of the dry RCA was also added (figure $3 a)$.

- In total, $1 \%$ of hydrated lime by weight of the dry RCA was added in the form of slurry ( $82.4 \%$ of distilled water and $17.6 \%$ of hydrated lime); $2 \%$ of Portland cement by weight of the dry RCA was also added (figure 3b).

\subsection{Testing program}

As mentioned above, to conduct the asphalt-aggregate adhesion analysis, two tests were performed: the rolling bottle method and the boiling water test.

The rolling bottle method consists of introducing a sample of loose bituminous mixture into a glass bottle filled with distilled water and rotating the sample for 24 hours. The percentage of asphalt that remains after rotation is determined. The results of this test are only useful in comparisons between samples because the rolling bottle method has no requirements for asphalt coating.

The boiling water test consists of introducing a sample of a loose bituminous mixture into distilled water and boiling the sample for 10 minutes. The percentage of aggregate that remains attached after boiling is determined. In this test, a minimum asphalt coating of $85 \%-90 \%$ is required to determine whether the asphalt-aggregate bond is satisfactory (Kiggundu and Roberts, 1988).

\section{Test results and discussion}

A total of twelve loose mixtures were studied following the two laboratory methods described above. Figure 4 shows the RCA-bitumen adhesion results for both laboratory methods. In the first analysis, the boiling water test displays better RCA-bitumen affinity results than the rolling bottle method. This is because of the different detachment mechanism prevailing in each of the two performance tests. In both tests, the water interacts with the sample. However, in the rolling bottle method, the beating of the aggregates during the rolling causes the detachment of bitumen. In the boiling water test, the detachment is caused by heating. The high temperatures 
during the boiling water test likely promote chemical reactions between the bitumen and the hydrated lime, resulting in a better adhesion with the RCA.

In general, lower penetration grade bitumen causes higher RCA-bitumen bonds. Therefore, as expected (Liu et al., 2014; Pasandín and Pérez, in press), the B40/50 displays a higher remaining bitumen coating for both tests, and the B150/200 displays the worst bitumen coverage.

From this laboratory evaluation, the use of hydrated lime in general does not improve the RCAbitumen adhesion. Notably, the control mixture (the sample comprised of only with Portland cement as filler) displays similar or better bitumen coverage results than those using hydrated lime. This result seems to contradict the conclusions obtained by other studies (Hicks, 1991) in which hydrated lime is the most effective additive against the action of water. Nevertheless, this conclusion was obtained for virgin aggregates and not for RCA. Thus, RCA seems to not follow the identical rules of virgin aggregates. This deviation is likely because of the attached mortar onto the RCA surface, which is mainly composed of Portland cement.

For the boiling water test, the hydrated lime applied to the SSD RCA displayed better coverage results (figure 5a), similar or slightly better than those obtained for the control mixture. Contrary to the rolling bottle method, this treatment displays the worst coverage results (figure 5b). Again, the prevailing detachment mechanisms in each performance test may explain this finding.

Three-way ANOVA (analysis of variance) was conducted using SPSS software (PASW Statistics 18) to determine the effect of the performance test, the penetration grade of the bitumen and the method of introducing hydrated lime in the mixture on the adhesion between asphalt and RCA. The remaining asphalt coating was the dependent quantitative variable, whereas the type of test (rolling bottle method or boiling water test), the asphalt penetration grade (B40/50, B60/70 and B150/200) and the method of introducing the hydrated lime in the mixture (as filler, applied to SSD RCA and as slurry) were qualitative factors.

The ANOVA results are displayed in table 2. Statistical analysis indicated that the type of test ( $\mathrm{p}$ $\leq 0.0001 \leq 0.05)$ and the use of treatment $(\mathrm{p}=0.026 \leq 0.05)$ significantly affects the asphalt-RCA 
adhesion, confirming the results observed in figure 4 . Nevertheless, the bitumen penetration grade is not statistically significant in the RCA-bitumen bond $(\mathrm{p}=0.051 \geq 0.05)$, contradicting the results observed in figure 4 . To refine the results, a Tuckey post hoc analysis was also conducted to analyse the influence of the bitumen penetration grade. The results are shown in table 3 . The penetration grade is statistically significant $(\mathrm{p}=0.05)$ only between the extreme penetration grades analysed, that is, between B40/50 and B150/200. Thus, to detect the effect of the grades, the differences between penetrations must be noticeable.

\section{Conclusions}

Based on the results of this research, the following conclusions can be drawn:

- Aggregate-asphalt bond tests influence the bitumen coverage results. Therefore, when analysing the RCA-bitumen bond, is recommended to conduct at least two different tests to generalize the findings.

- As was expected, a higher asphalt penetration grade correlates to a lower RCA-asphalt adhesion. Nevertheless, these differences are significant when the penetration grades differences are noticeable (for example B40/50 versus B150/200).

- Unexpectedly, conclusions from other studies were not confirmed; in general, mixtures composed of Portland cement display better RCA-asphalt bond than mixtures in which hydrated lime is introduced.

These findings were obtained from the limited research conducted. Therefore, further investigations are required to resolve issues such as why the RCA functions differently than natural aggregates when using hydrated lime as an anti-stripping agent.

\section{Acknowledgements}

The authors acknowledge the Spanish Ministry of Education and Science for sponsoring this research through Project BIA2010-17751. The authors thank Repsol for supplying the asphalt binder. The authors thank Tudela Veguín for supplying the Portland cement.

The authors thank TEC-REC for supplying the RCA. The authors thank the Unidade de Espectroscopia Molecular (UEM) of the Universidade da Coruña (UDC) for performing the FTIR-ATR tests. 


\section{References}

AENOR (2011). UNE-EN 12697-11. "Métodos de ensayo para mezclas bituminosas en caliente. Parte 11: Determinación de la afinidad entre áridos y betún”. Airey, G.D.; Collop, A.C.; Zoorob, S.E. and Elliot, R.C (2008). The influence of aggregate, filler and bitumen on asphalt mixture moisture damage. Construction and Building Materials 22, 2015-2024.

ASTM “D 3625-96 (2005). Standard Practice for Effect of Water on Bituminous-Coated Aggregate Using Boiling Water.

Button, J.W. and Epps, J.A. (1983). Evaluation of methods of mixing lime in asphalt paving mixtures. Texas Transportation Institute.

Caro, S, Masad, E., Bhasin, A. and Little, D.N. (2008). Moisture susceptibility of asphalt mixtures, Part 1: mechanisms. International Journal of Pavement Engineering 9.2: 81-88. Epps, Jon; Berger, Eric; Anagnos and James N. (2003). Treatments. Moisture Sensitivity of Asphalt Pavements: A National Seminar. February 4-6. San Diego, California. Transportation Research Board.

Hicks, R.G. (1991). Moisture damage in asphalt concrete. Transportation Research Board 175. Jo, Myung-Chan, Tarrer, Arthur R., Jeon, Young W., Park, Sang Joon and Yoon, Hyon Hee (1997). Investigation of the effect of aggregate pretreatment with antistripping agents on the asphalt-aggregate bond. Petroleum Science and Technology 15:3-4: 245-271.

Kiggundu, B.M. and Roberts, F.L. (1988). Stripping in HMA mixtures: state-of-the-art and critical review of test methods. NCAT Report 88-02.

Kim, Yong-Rak; Pinto, Ingrid and Park, Seong-Wan (2012). Experimental evaluation of antistripping additives in bituminous mixtures through multiple scale laboratory test results. Construction and Building Materials 29, 383-393. Lesueur, Didier; Petit, Jöelle and Ritter, Hans-Josef (2012) The mechanisms of hydrated lime modification of asphalt mixtures: a state-of-the-art review. Road Materials and Pavement Design 
Liu, Yawen; Apeagyei, Alex; Ahmad, Naveed; Grenfell, James and Airey, Gordon (2014).

Examination of moisture sensitivity of aggregate-bitumen bonding strength using loose asphalt mixture and physico-chemical surface energy property tests. International Journal of Pavement Engineering 15 (7), 657-670.

Lu, Xiaohu and Isacsson, Ulf (2002). Effect of ageing on bitumen chemistry and rheology. Construction and Building Materials 16 (1), 15-22.

Paranavithana Sumeda and Mohajerani Abbas (2006). Effects of recycled concrete aggregates on properties of asphalt concrete. Resources, Conservation and Recycling 48, 1-12.

Pasandín, A.R. and Pérez, I. Effects of the asphalt penetration grade and the mineralogical composition on the asphalt-aggregate bond. Petroleum Science and Technology (in press). Pérez I., Gallego J., Toledano M. and Taibo, J. (2010). Asphalt mixtures with construction and demolition debris. Proceedings of the Institution of Civil Engineers. Transport 163, 165-174. Pérez I., Pasandín A.R and Gallego J. (2012a). Stripping in hot mix asphalt produced by aggregates from construction and demolition waste. Waste Management and Research 30 (1), 3 11.

Pérez I., Pasandín A.R. and Medina L. (2012b). Hot mix asphalt using C\&D waste as coarse aggregates. Materials and Design 36, 840-846.

Pérez I., Toledano M., Galego J. and Taibo J. (2007). Mechanical properties of hot mix asphalt made with recycled aggregates from reclaimed construction and demolition debris. Materiales de Construcción 57 (285), 17-29.

Qin, Qian; Schabron, John F.; Boysen, Ryan B. and Farrar, Michael J. (2014). Field aging effect on chemistry and rheology of asphalt binders and rheological predictions for field aging. Fuel $121(1), 86-94$.

Zhu, Q.; Zhou, C. and Wang, S.Y. (2014). The Regeneration of Aged SBS Modified Asphalt via Re-reticulating SBS Particles Under Gamma Irradiation. Petroleum Science and Technology 32 (12), 1490-1496. 
Table 1

RCA properties

\begin{tabular}{lll}
\hline Property $(*)$ & Standard & Result \\
& & \\
\hline$\rho \mathrm{\rho a}\left(\mathrm{g} / \mathrm{cm}^{3}\right)$ & EN-1097-6 & 2.63 \\
$\mathrm{WA}_{24}(\%)$ & EN 1097-6 & 5.08 \\
$\mathrm{SE}(\%)$ & EN 933-8 & 67 \\
$\mathrm{LA}(\%)$ & EN 1097-2 & 32 \\
\hline
\end{tabular}

(*) pa: bulk specific gravity

$\mathrm{WA}_{24}$ : water absorption

SE: sand equivalent

LA: Los Angeles abrasion coefficient

Table 2

ANOVA results: the effects of the type of test, bitumen penetration grade and use of hydrated lime in the RCA-asphalt bond

\begin{tabular}{llllll}
\multicolumn{1}{c}{ Source of Variation } & \multicolumn{1}{c}{ SS } & DF & MS & F & p-value \\
\hline MAIN EFFECTS & & & & & \\
\hline A: type of test & $1,276.042$ & 1 & $1,276.042$ & 53.261 & 0.000 \\
\hline B: bitumen penetration grade & 243.750 & 2 & 121.875 & 5.087 & 0.051 \\
\hline C: use of hydrated lime & 469.792 & 3 & 156.597 & 6.536 & 0.026 \\
\hline INTERACTIONS & & & & & \\
\hline A*B & 189.586 & 2 & 94.792 & 3.957 & 0.080 \\
\hline A*C & 803.125 & 3 & 267.708 & 11.174 & 0.007 \\
\hline B*T & 139.583 & 6 & 23.264 & 0.971 & 0.514 \\
\hline RESIDUAL & 143.750 & 6 & 23.958 & & \\
\hline TOTAL & $3,265.628$ & & & &
\end{tabular}

(*) SS: sum of squares; DF: degrees of freedom and MS: mean square

Table 3

Tuckey post-hoc analysis: the effects of the bitumen penetration grade on the RCAasphalt bond

\begin{tabular}{c|l|l}
\multicolumn{2}{c|}{ Bitumen } & $\mathrm{p}$ \\
\hline \multirow{2}{*}{$\mathrm{B} 40 / 50$} & $\mathrm{~B} 60 / 70$ & 0.736 \\
\cline { 2 - 3 } & $\mathrm{B} 150 / 200$ & 0.050 \\
\hline \multirow{2}{*}{$\mathrm{B} 60 / 70$} & $\mathrm{~B} 40 / 50$ & 0.736 \\
\cline { 2 - 3 } & $\mathrm{B} 150 / 200$ & 0.132 \\
\hline \multirow{2}{*}{$\mathrm{B} 150 / 200$} & $\mathrm{~B} 40 / 50$ & 0.05 \\
\cline { 2 - 3 } & $\mathrm{B} 60 / 70$ & 0.132
\end{tabular}


Figure 1

FTIR-ATR spectra for B40/50, B60/70 and B150/200

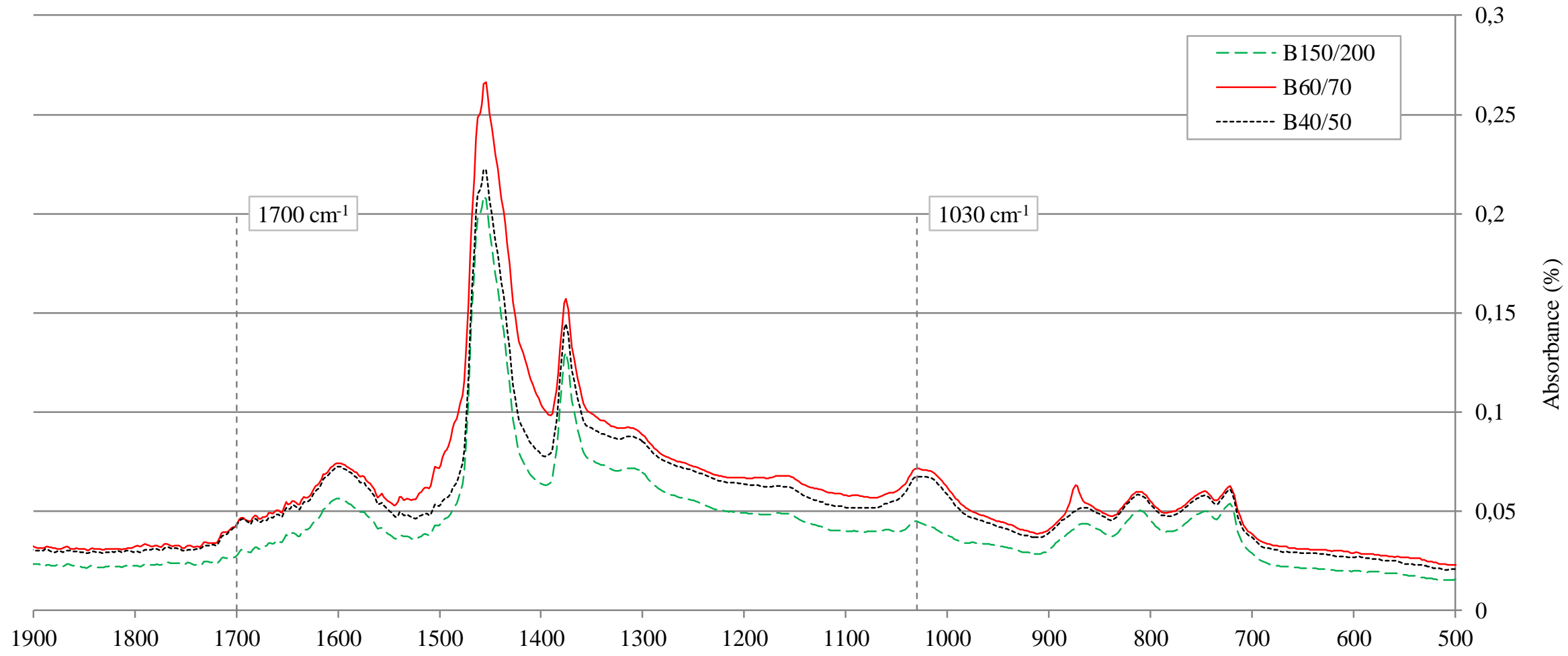

Wavenumber $\left(\mathrm{cm}^{-1}\right)$ 
Figure 2

CL-90-S grain size distribution

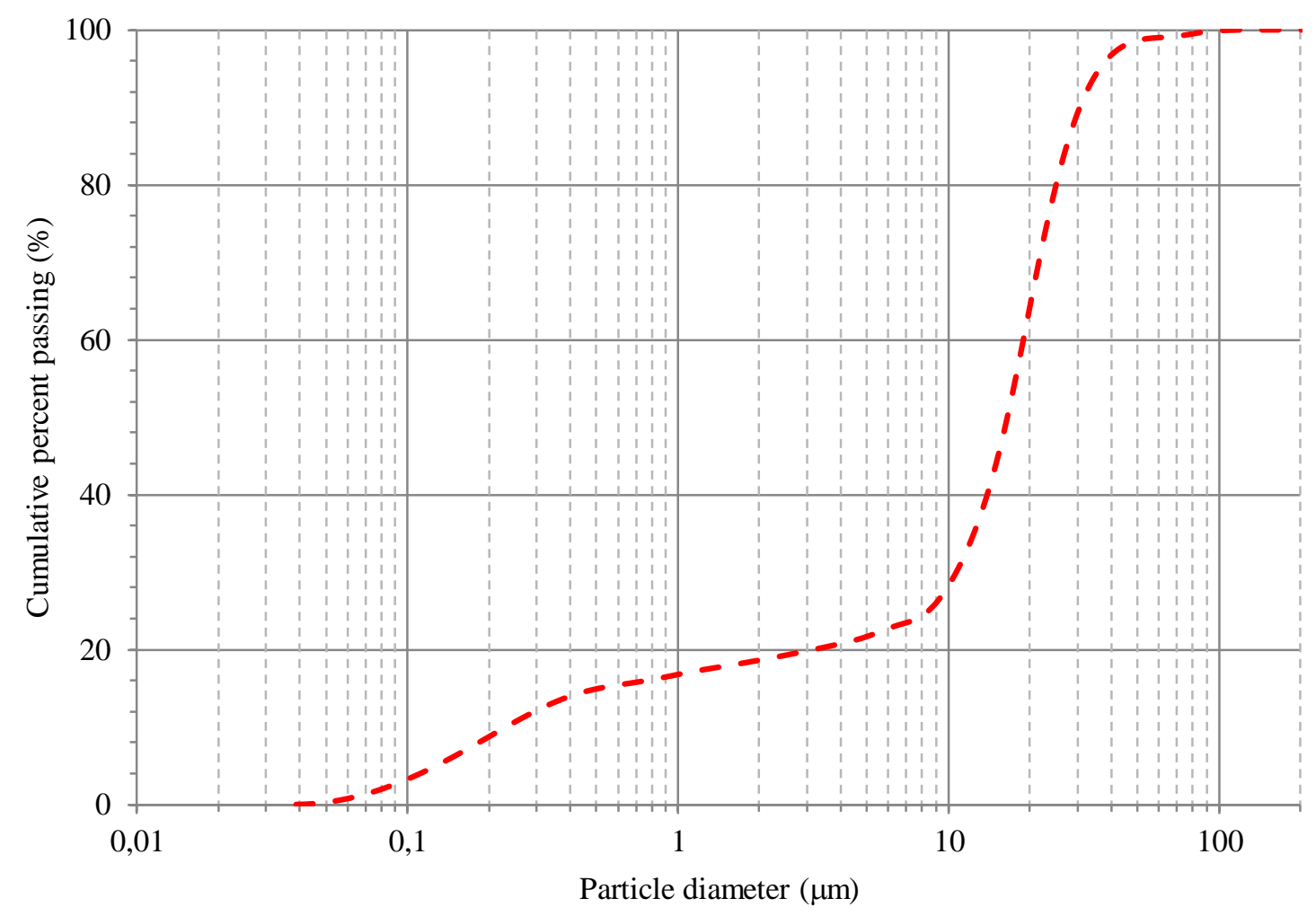


Figure 3

Pretreated RCA before mixing with bitumen: a) $1 \%$ of hydrated lime to SSD condition RCA and b) RCA with hydrated lime in the form of slurry
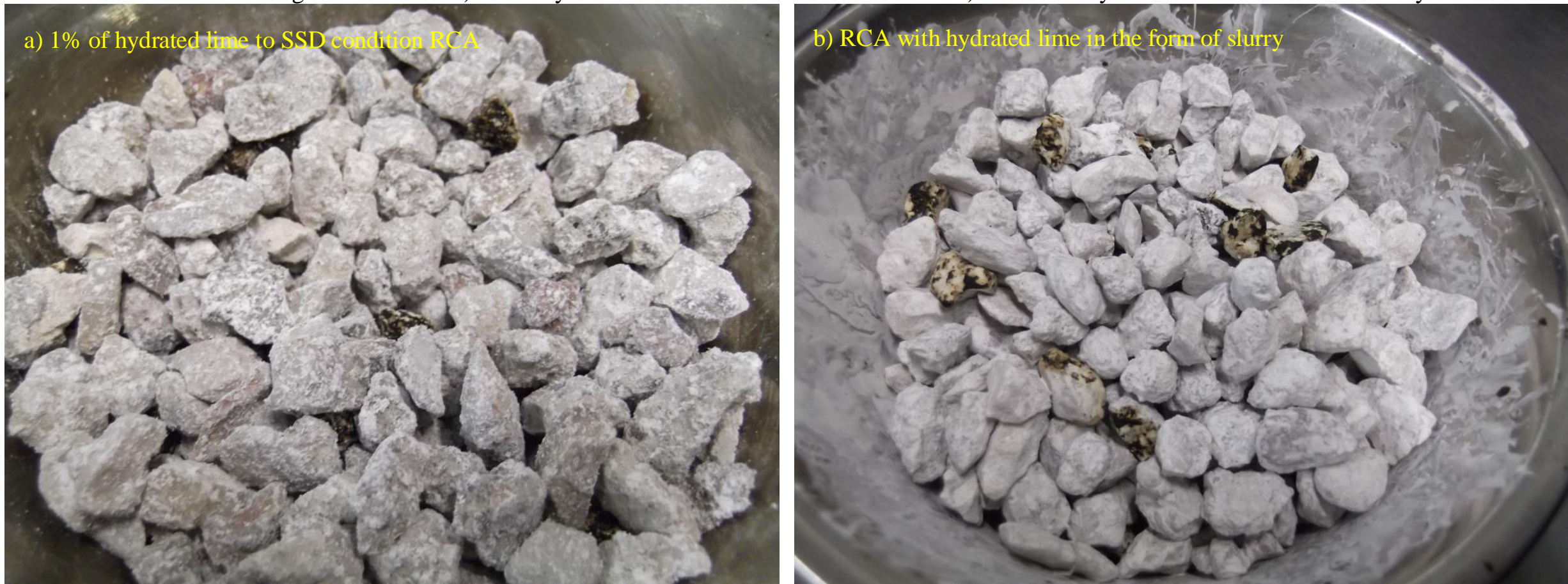
Figure 4

RCA-bitumen adhesion results

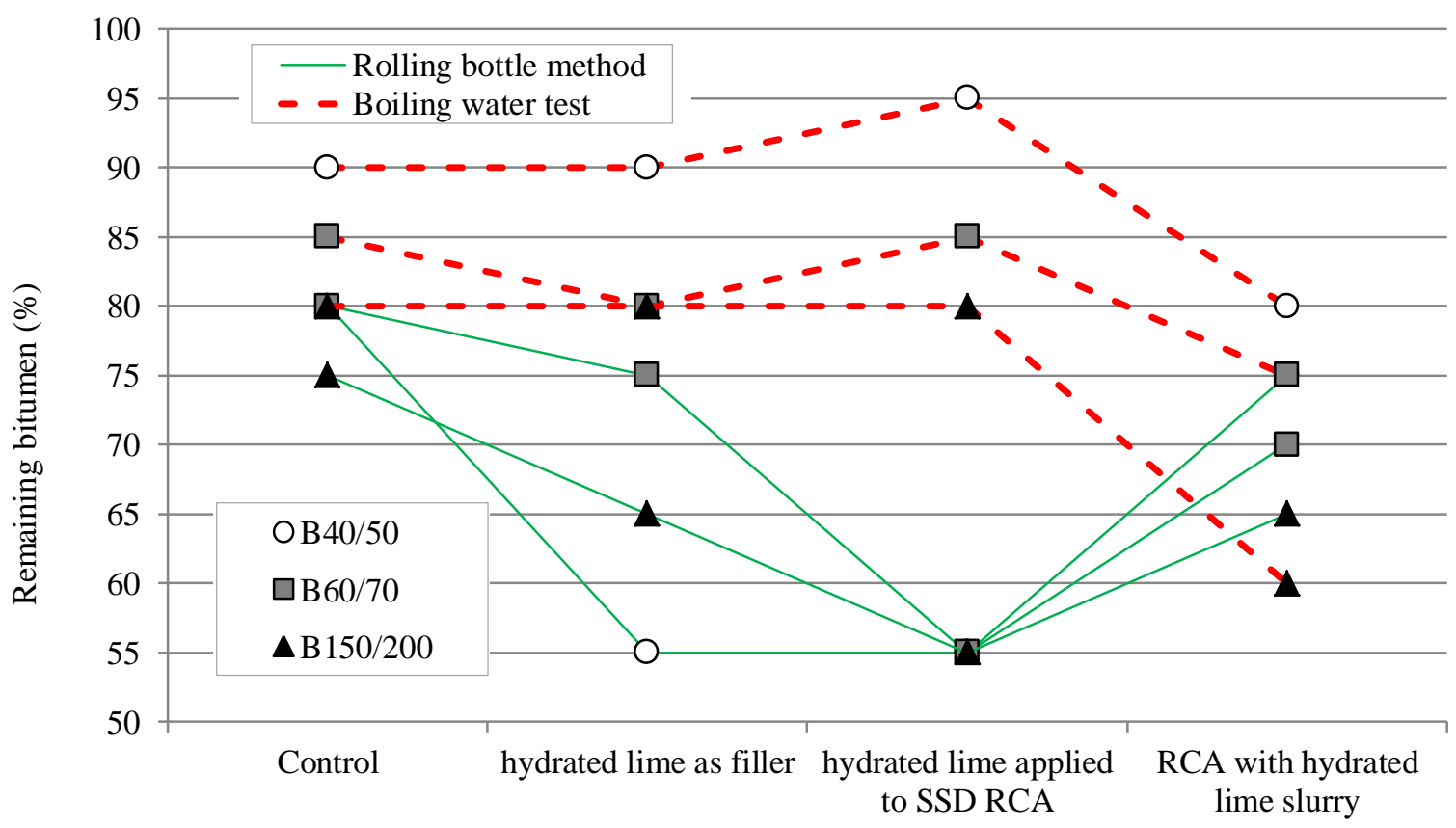

Sample 
Figure 5

Hydrated lime applied to SSD RCA using B40/50: a) boiling water test results and b) rolling bottle method results

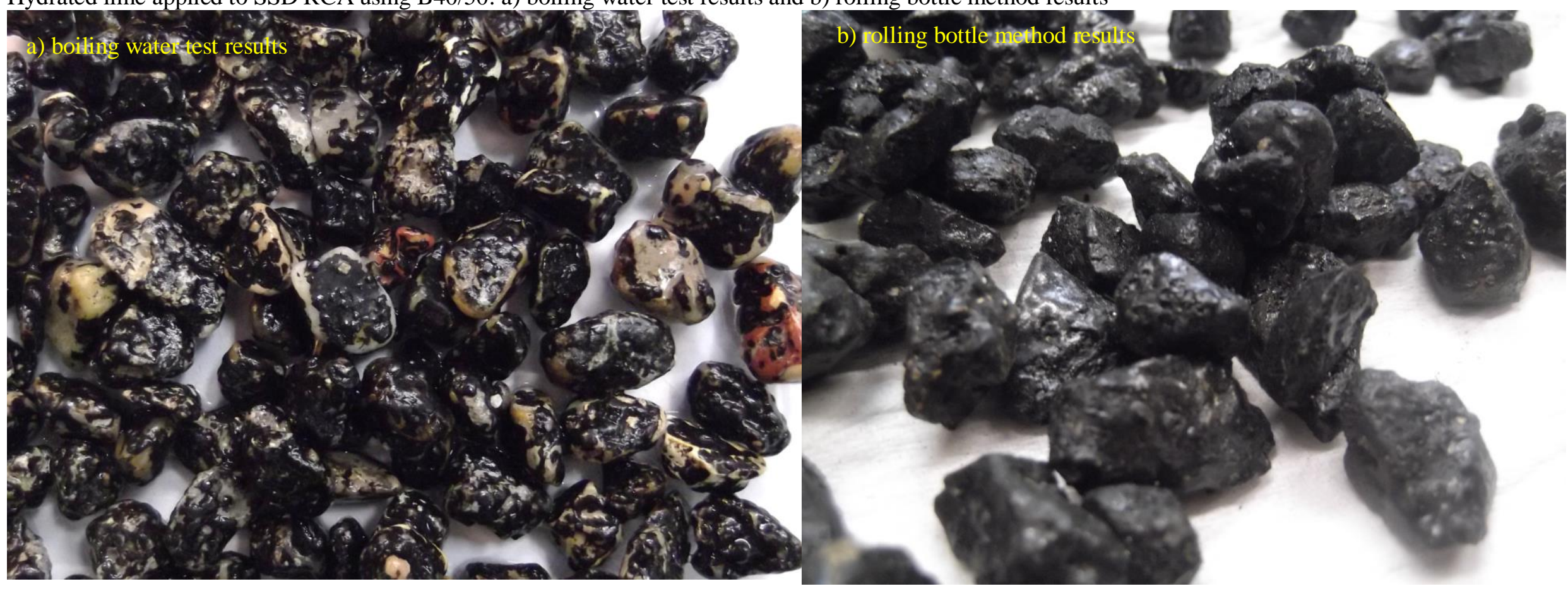

